Recebido: $11 / 01 / 2015$

Aprovado: 21/03/2015

\title{
O Iluminismo nos livros didáticos brasileiros
}

Guilherme Domingues Gonçalves*

Resumo: O objetivo deste artigo é traçar um panorama do tema lluminismo tal como é transmitido no Ensino Médio brasileiro. Para isso, serão analisados alguns livros didáticos aprovados pelo Programa Nacional do Livro Didático (PNLD). Nessa análise, dialoga-se com a historiografia mais recente sobre o assunto, principalmente as linhas interpretativas que ganham força nos anos 2000 .

Palavras-chave: Iluminismo; Livro didático; Historiografia.

Abstract: This article aims on a comprehensive presentation of the Enlightenment as it is taught in ordinary Brazilian High School curriculums. For analisys purposes approved-only National Textbooks Programme (PNLD) will be taken into consideration. Among the data collected a direct dialogue will be established with the newest theories of historiography focusing on the main schools of thought as of the year 2000 onwards.

Keywords: Enlightment; Textbooks; Historiography.

*Bacharel e licenciado em História pela Universidade de Brasília. E-mail para contato: guilhermegoncales@gmail.com 
O objetivo deste artigo é traçar um panorama do tema Iluminismo ${ }^{1}$ tal como é transmitido no Ensino Médio brasileiro. Para isso, serão analisados alguns livros didáticos aprovados pelo Programa Nacional do Livro Didático (PNLD). Nessa análise, dialoga-se com a historiografia mais recente sobre o assunto, principalmente as linhas interpretativas que ganham força nos anos 2000.

A transmissão do conhecimento pode ser realizada de diversas formas. Observa-se hoje, no campo da educação, inúmeras possibilidades para aquisição desse conhecimento, quer seja por meio da internet ou por outras mídias. No entanto, no campo da educação básica, o maior e mais legitimado meio de transmissão do conhecimento ainda é o livro didático. Sem desmerecer o papel do professor e das outras formas de aquisição do saber, o livro didático parece ainda imperar nas salas de aulas como a mais válida fonte de consulta e aprendizado.

O livro didático é "um produto cultural dotado de alto grau de complexidade" (MIRANDA e LUCA, 2004: 124). Produto comprometido com diferentes interesses historiográficos, econômicos e ideológicos, por exemplo - de diversos sujeitos, entre os quais se firma como mediador nas práticas culturais. Afinal, é preciso lembrar que, indissociáveis da produção, da circulação e do uso do livro didático, encontram-se relações humanas, sociais, que lhe determinam as configurações materiais e as formas de leitura assumidas por alunos e professores (Cf. Munakata. apud ROCHA; MAGALHÃES e GONTIJO, 2009: 281292).

Deveria ser desnecessário endossar aqui, em um trabalho de história, a postura, que irá se adotar, de se considerar o livro didático como objeto histórico - isto é, relacionado a certos contextos socioculturais situados no tempo. No entanto, diante da posição assumida por muitos, que reduzem este objeto à condição de mero repositório de distorções, erros e manipulações, não é redundante fazê-lo. Acredita se, portanto, que o livro didático aparece como uma mercadoria muito específica, que reflete na sua forma, em seus significados e usos, os sujeitos que os produzem e deles se apropriam das mais diferentes maneiras ao longo do tempo.

Para além da transmissão do saber, o livro didático carrega em si e expressa valores culturais e ideológicos. O livro é fruto de seu tempo histórico e isso deve ser também motivo de problematização. Compreender o livro didático e as condições de sua produção, as

\footnotetext{
${ }^{1}$ Iluminismo é um termo utilizado na historiografia, em geral, para caracterizar, de forma homogênea, a filosofia do século XVIII europeu.
} 
concepções e os interesses do seu tempo nos ajudam a pensar no tipo de discurso presente neles.

Hoje, os livros didáticos abarcam uma volumosa fatia do mercado editorial tanto em tiragem quanto em venda. O Programa Nacional do Livro Didático (PNLD), que tem como finalidade distribuir gratuitamente estes livros aos alunos de escolas estaduais, municipais, federais e de educação especial públicas, comunitárias e filantrópicas, impulsionam esse sucesso editorial. A seleção dos livros é realizada pelo Ministério da Educação, e o Governo Federal executa a compra. Mecanismo similar é aplicado ao Programa Nacional do Livro Didático para o Ensino Médio (PNLEM).

No presente trabalho são analisados três livros didáticos produzidos para o Ensino Médio, todos editados pela editora FTD, e de produção recente. Os três livros foram aprovados pelo PNLEM e dois figuram na lista dos mais adquiridos pelo Governo Federal para distribuição no ano de 2013, são eles: Novo olhar - História 2 que teve a venda de 48.204 exemplares e o Estudos de História: Ensino Médio, volume único com a venda de 22.716 exemplares $^{2}$. O outro livro analisado não figura nessa listagem, entretanto foi usado na pesquisa para se perceber como um conteúdo pode ser abordado de formas diversas em livros publicados pela mesma editora, mas de autores distintos. Os livros selecionados para análise permitem uma pequena, mas significativa ideia de como se transmite o tema Iluminismo no Ensino Médio brasileiro.

As obras selecionadas estão à venda no mercado, podem ser adotadas por qualquer instituição de ensino e possuem ampla distribuição pelo país. Cabe ressaltar a presença, neles, de interesses que estão além das propostas pedagógicas e da obtenção de certas capacidades instituídas pelo Parâmetros Curriculares Nacionais (PCN), dentre elas a influência do vestibular para a escolha dos temas e suas formas de abordagens visando, ao final, o melhor desempenho do aluno nas seleções para ingresso nas universidades.

De modo geral, o conteúdo Iluminismo é abordado nos livros didático de uma forma homogênea, ocupando geralmente poucas páginas dos livros e dividindo espaço com outros assuntos. O Iluminismo é conceitualizado de forma reducionista e sempre associado a outros

\footnotetext{
${ }^{2}$ Esses valores de referência foram divulgados pelo Fundo Nacional de Desenvolvimento da Educação no site: http://www.fnde.gov.br/programas/livro-didatico/livro-didatico-dadosestatisticos?highlight=YTo2OntpOjA7czo1OiJsaXZybyI7aToxO3M6OToiZGlkw6F0aWNvIjtpOjI7aToyMDEz O2k6MztzOjE1OiJsaXZybyBkaWTDoXRpY28iO2k6NDtzOjIwOiJsaXZybyBkaWTDoXRpY28gMjAxMyI7a To1O3M6MTQ6ImRpZMOhdGljbyAyMDEzIjt9 - consultado pela última vez dia 19 de agosto de 2013.
} 
conteúdos, como, principalmente, a revolução científica do século XVII, que teria possibilitado o surgimento de pensamentos esclarecidos em toda a Europa.

No livro Estudos de História (FARIA; MIRANDA e CAMPOS, 2010), o conteúdo é abordado no capítulo seis, com o título "A revolução científica do século XVII e o Iluminismo", com quatro páginas dedicadas ao assunto. A partir de uma descrição do que foi o desenvolvimento científico do século XVII ao XVIII, os autores observam que nesse período algumas noções se estabeleceram, como a de que o universo não era estático e que a interferência divina deveria ser aceita apenas na sua origem. Tais noções teriam sido fundamentais para o surgimento do movimento iluminista que veio a se desenvolver no século XVIII.

Os autores afirmam que o Iluminismo é um conceito complexo e baseiam sua explicação e conceituação na obra de Antônio Carlos do Amaral Azevedo (Cf. AZEVEDO, 1999: 246 - 247) que, em traços genéricos, tenta explicar o que foi tal fenômeno histórico. Conforme Azevedo, o Iluminismo é um movimento que priorizou a razão e "em torno do qual se desenvolve o tema do progresso, a que se acrescenta o da civilização e o da cultura" (FARIA; MIRANDA e CAMPOS, op.cit.:149) Menciona o caráter antropocêntrico do movimento para lembrar que o homem é uma preocupação constante dos iluministas e a ideia do progresso é reafirmada, adquirindo um caráter quase onipresente para os homens que viviam nessa época. O Iluminismo também é caracterizado, pelos autores, como um fenômeno burguês e dele "decorre o pensamento político e econômico da época conhecido como liberalismo" (Idem, ibidem: 150).

Após essa caracterização do objeto estudado, os autores apresentam em poucas linhas, "os mais significativos pensadores liberais" (Idem, ibidem: 150), que seriam: John Locke, inglês precursor do liberalismo e crítico do regime absolutista; Voltaire, francês, crítico do absolutismo e do clero, defensor dos direitos individuais, mas que não poderia ser entendido como um democrata; Jean-Jacques Rousseau, suíço, apontado como elemento estranho ao grupo e seria mais do que um liberal, segundo os autores, Rousseau seria um democrata; Adam Smith, escocês, defensor do trabalho como gerador de riqueza, defendia sua divisão para se obter maior produtividade. Além desses, são citados Montesquieu, os enciclopedistas (Diderot e D'Alembert) e os fisiocratas.

Ao fim, o livro termina com a explicação do conceito despotismo esclarecido. De forma confusa, afirma-se que nos Estados onde as burguesias não tinham condições para o seu desenvolvimento, os governantes assumiram a iniciativa de uma "aparente reforma 
administrativa" (Idem, ibidem: 150). Medidas que podem ser resumidas pelo "incentivo às atividades econômicas, a tolerância religiosa, o combate ao analfabetismo e o incentivo à educação científica" (Idem, ibidem: 151). As reformas pombalinas em Portugal e o governo de Catarina II no Império Russo são, segundo os autores, exemplos de governos que impulsionaram as reformas.

O livro História, sociedade e cidadania (BOULOS JÚNIOR, 2011), editado em volume único, aborda o Iluminismo no capítulo 34. São dedicadas nove páginas para o assunto. $\mathrm{O}$ autor afirma que o termo mais apropriado seria Ilustração ao invés de Iluminismo, mas adota ambos para se referir a tal fenômeno. Dialogando com o autor Francisco José Calazans Falcon (FALCON, 1994: 96), Alfredo Boulos caracteriza o Iluminismo pela defesa da crença na razão humana e no seu potencial. Essa razão, aplicada a qualquer atividade humana destruía a ignorância, combatia os preconceitos e o fanatismo religioso. Boulos destaca a existência de uma crença otimista no progresso da humanidade entre os iluministas. Outro ponto defendido no livro é o fato da França ser o principal centro de produção e propagação dos ideais iluministas por toda a Europa ocidental.

Com esse conceito formulado, o capítulo descreve as ideias de alguns pensadores iluministas. São escolhidos três em um primeiro momento: Voltaire, Montesquieu e Rousseau. Em relação a Voltaire são destacados a sua crítica ao Antigo Regime, o seu anticlericalismo e sua defesa "incansável da liberdade de pensamento e de expressão" (BOULOS, op. cit.: 433). Montesquieu é lembrado por sua obra $O$ espírito das leis e sua teoria dos três poderes (Executivo, Legislativo e Judiciário). Já Rousseau é lembrado pela sua originalidade e pelas suas teorias do contrato social e da vontade geral. Ainda é analisada a questão da enciclopédia, que teria sido a maior divulgadora do saber iluminista.

Boulos associa o Iluminismo à economia. Afirma que a intervenção do Estado na economia sofreu diversos ataques pelos fisiocratas e por Adam Smith. Smith é tratado como o pai do liberalismo, defensor do livre comércio. O autor associa a expressão mão invisível, presente na obra de Smith, às leis de mercado.

Ainda é abordado o tema despotismo esclarecido como uma forma de apropriação das ideias iluministas por alguns monarcas absolutistas que "pretendiam modernizar seus países, diminuir as tensões sociais e, acima de tudo, ampliar seu poder, prestígio e fama" (Idem, ibidem: 436). São citados quatro reformadores: Frederico II, da Prússia; José II, da Aústria; Catarina II, da Rússia e Marquês de Pombal, primeiro ministro do rei D.José I de Portugal. Todos esses realizaram reformas modernizadoras em seus governos e por isso eles seriam 
enquadrados nesse conceito. $\mathrm{O}$ autor ainda coloca que tal conceito foi primeiramente utilizado pelos historiadores do século XIX para caracterizar esse tipo de governo.

O último livro didático a ser analisado é o que dedica o maior número de páginas para o assunto e é, dentre os analisados, o mais adquirido pelo Governo Federal. Intitulado Novo olhar - História (PELLEGRINI; DIAS e GRINBERG, 2011), o segundo volume da coleção aborda o tema no sétimo capítulo de título "O Iluminismo" e, ao longo de 20 páginas os autores vão buscar desde a origem desse pensamento até a crítica contemporânea ao fenômeno.

Os autores do livro caracterizam o conceito de Iluminismo partindo de um diálogo com os autores Kalina Vanderlei Silva e Maciel Henrique Silva (SILVA e SILVA, 2006: 210), no entanto, não ficam restritos apenas aos dois, visto que recorrem também a um autor da época para esclarecer o que era o Iluminismo. Tratando o assunto dentro do campo da história das ideias, os autores recuperam o texto de Immanuel Kant do ano de 1784 "para definir a filosofia dominante na Europa ocidental no século XVIII" (PELLEGRINI; DIAS e GRINBERG, Op. cit.: 144) e trazem a ideia de que o Iluminismo configura um período de esclarecimento e um momento de criação das condições para a autonomia do indivíduo. Afirmam que o Iluminismo foi um fenômeno histórico de dimensão geográfica relativamente largo, abrangendo França, Itália, Escócia, Polônia, América do Norte e outros países. Citam o termo philosophes para se referir a todos os filósofos e pensadores do período.

Segundo o livro didático, o Iluminismo foi um movimento que deu importância ao pensamento racional, fez duras críticas aos dogmas religiosos e ao poder absoluto dos monarcas fazendo criticas a autoridade religiosa e ao autoritarismo de qualquer tipo e opondose ao fanatismo. Além disso, os filósofos questionaram as bases do Antigo Regime contribuindo "para a desestruturação gradual desse regime por toda a Europa" (Idem, ibidem: 144). Atribuíram, dessa forma, um caráter revolucionário às ideias iluministas e associaramnas à Revolução Francesa, à Revolução Americana e a algumas rebeliões no Brasil, a exemplo da Conjuração Mineira e a Conjuração Baiana.

O livro busca os fundamentos da base teórica iluminista no século XVII na Revolução Científica. Citando pensadores como Galileu, Francis Bacon, Descartes e Isaac Newton, os autores explicam que, ao criar um meio racional para analisar e compreender os fenômenos naturais, esses autores abriram o caminho para a forma de se pensar no "século das luzes".

$\mathrm{O}$ autor não separa a exposição do conteúdo por pensadores, mas sim por eixos temáticos. O primeiro a ser apresentado é "a crítica ao absolutismo", citando Montesquieu, 
Locke e Rousseau, que, segundo o texto, "contestaram o autoritarismo e a ideia da origem divina do poder do rei, além de condenarem os privilégios da nobreza e do clero" (PELLEGRINI; DIAS e GRINBERG, Op. cit.: 145). Explicam a teoria dos três poderes de Montesquieu como uma forma de se libertar do despotismo, instituindo os poderes executivo, legislativo e judiciário. Um pequeno espaço é destinado à explicação do despotismo esclarecido, que seria uma mistura de práticas absolutistas com as ideias iluministas exemplificadas pela reforma do Marquês de Pombal em Portugal, período que é referido como despotismo pombalino.

O próximo tema abordado é a crítica à igreja católica. De acordo com os autores, os pensadores setecentistas criticavam a superstição, o fanatismo e a intolerância religiosa, além de uma crítica aos dogmas religiosos que impossibilitavam a liberdade de pensamento. Os autores analisam a crítica de Voltaire, reafirmando a crença de que a razão deveria ocupar o lugar da superstição e condenando a intolerância religiosa por causar mortes e destruição. É também mencionada a enciclopédia e sua importância para a divulgação do pensamento do século das luzes.

Na sequência, é abordado o tema liberalismo. Nesse momento, os autores mostram a influência iluminista sofrida pela burguesia, destacando o início da crítica principalmente, às práticas econômicas dos Estados que dificultavam o seu enriquecimento. Dessa forma, segundo o autor, os burgueses buscaram o apoio das camadas mais populares e incitaram a luta pela liberdade individual, estabelecendo, assim, os fundamentos do liberalismo. São citados Locke e os fisiocratas, como pensadores que ajudaram a criar a ideia de liberalismo na economia e na política. Todavia, o principal teórico do liberalismo econômico seria Adam Smith, cuja obra Uma investigação da natureza e das causas da riqueza das nações (1776) teria postulado os princípios desse sistema econômico, como a livre concorrência.

O capítulo termina com "a crítica contemporânea ao iluminismo", apresentando o início de um movimento que ganhou força em meados do século XX. Os autores do livro didático mostram que os pensadores contemporâneos começaram a criticar abertamente o racionalismo, o cientificismo e o culto ao progresso. A Escola de Frankfurt e os teóricos da pós-modernidade são citados como contestadores pioneiros dessa racionalidade iluminista.

Após essa breve análise da abordagem do Iluminismo em livros didáticos distintos, pode-se perceber, de maneira geral, certas aproximações e associações semelhantes que os autores fazem criando uma espécie de denominador comum em relação ao tema, o que possibilita a cristalização de certa perspectiva sobre o assunto. Ao final, percebe-se que o 
Iluminismo, nesses livros, foi um evento homogêneo, europeu, contra o Antigo Regime e os dogmas da igreja católica, que subverteu formas tradicionais de pensar, deu certa voz a burguesia e abriu terreno para o pensamento liberal. Não se pode também deixar de lado a influência da Revolução Científica do século XVII para a iniciação desse movimento do século das luzes.

Cabe salientar a recorrência aos mesmos pensadores da época, aos quais o espaço destinado para explicar o conteúdo é muito similar. Voltaire é recuperado no momento em que se aborda a intolerância religiosa e a crítica à igreja católica, Montesquieu é lembrado pela sua teoria dos três poderes, Adam Smith é associado ao liberalismo econômico, sendo considerado o pai de tal doutrina, Diderot e D'Alambert são apenas os organizadores da enciclopédia e os demais autores citados nos livros se encaixam em um único nicho. Não é possível, dessa forma, perceber que os interesses desses pensadores eram diversificados, não se restringiam a temas políticos e econômicos, e que seus escritos informam sobre uma época em que foram produzidos, dentro de um campo de possibilidades existente.

Nos últimos anos, a abordagem em relação ao tema Iluminismo no campo acadêmico ganhou novas perspectivas de análises. Autores como Gertrude Himmelfarb, Dorinda Outram, Charles Withers, Jonathan Israel, David Sorkin e outros trouxeram novos horizontes de estudos sobre o tema. O Iluminismo ganha uma concepção plural, contrapondo-se principalmente a uma historiografia dos anos de 1970 "que tendeu a reduzir, em um sistema de ideias uniformes, coesas e homogêneas, os vários iluminismos ocorridos no século XVIII" (CARVALHO, 2013: 2) - tendência que ainda persiste na concepção do tema nos livros didáticos. A ideia presente em alguns autores, entre eles Peter Gay (GAY, 1996), de que havia uma grande quantidade de filósofos no século das luzes, mas apenas existiu um Iluminismo, ainda parece ser um guia para a elaboração e abordagem do tema nos materiais de ensino brasileiro.

A historiadora Gertrude Himmelfarb defende que o Iluminismo foi plural e que nem de longe pode ser entendido como um movimento de ideias homogêneo. A autora coloca no prefácio de seu livro Os caminhos da modernidade (HIMMELFARB, 2011) que se deve pensar nesse movimento intelectual no plural até mesmo na sua denominação, passando do singular iluminismo para iluminismos. A autora propõe-se a analisar o Iluminismo em três localidades geográficas: a França, a Inglaterra e os Estados Unidos. Com isso, quebra a centralidade francesa para a produção e divulgação das ideias ilustradas e destaca a importância inglesa no movimento. Ao mesmo tempo, ressalta que esse seria um "iluminismo 
muito diferente daquele criado pelos franceses" (HIMMELFARB, Op. cit.: 13). Em se tratando de conceitos, Gertrude não denomina todos os pensadores da época o philosophes. Segundo a autora, esse termo se encaixa no contexto das luzes francesas e o termo correto para se referir a um pensador inglês seria filósofo moral. Percebe-se assim toda uma preocupação com as particularidades existentes nas diferentes formas de ilustração e a tentativa de superar interpretações generalistas.

Além de Himmelfarb, outros autores destacam a importância dessa dilatação geográfica do movimento. Charles Withers defende a ideia do Iluminismo como um processo geográfico, tanto no sentido físico, espacial, quanto em um sentido de viagens das ideias, de circulação das ideias. Withers afirma que reduzir a compreensão do Iluminismo à questão nacional impossibilita perceber as diferenças internas e as diversas conexões entre nações. $\mathrm{O}$ Iluminismo deve ser pensado para além da nação, deve ser compreendido por sua apropriação em cada contexto intelectual. Foi um movimento intelectual que apresentou diversas nuances e que sofreu diversas formas de ressignificação dentro de uma tradição compartilhada por um grupo de pessoas ou país.

Muitos outros pesquisadores refletiram sobre a abordagem em torno do Iluminismo. As revisões historiográficas que começaram a ser feitas desde 1970 colocaram em xeque a visão homogênea e de coerência interna do movimento intelectual europeu do século XVIII. No meio acadêmico, atualmente, observa-se uma reação à interpretação do Iluminismo como um movimento de ideias homogêneo; privilegia-se a diversidade e as particularidades do pensamento setecentista europeu. As pesquisas recentes sobre o assunto levam em conta as características particulares e uma perspectiva plural em relação a esse fenômeno histórico. $\mathrm{O}$ Iluminismo não é um conceito fechado. Trata-se, antes, de um amplo debate de ideias e não deve ser compreendido como um projeto acabado. Da mesma forma, não deve ficar vinculado a um único grupo de filósofos ou a uma única localidade geográfica.

As orientações curriculares para o ensino da história no ensino médio têm como objetivo desenvolver o senso crítico e fornecer instrumentos que possibilitem ao aluno compreender como os discursos sobre o passado são construídos. Sabe-se que a prática é bem diferente das propostas defendidas. Ao analisar o conteúdo dos livros didáticos, comprova-se que as orientações curriculares pesam muito pouco em relação a outros interesses que envolvem a produção e a venda do livro didático no Brasil. Não se defende uma transposição didática acrítica do conhecimento acadêmico para o conhecimento escolar, pois se sabe que os objetivos e a forma da produção historiográfica acadêmica diferem-se muito da escolar. 
Entretanto, uma sintonia entre o que se produz nas universidades e o que se produz para a educação básica deve ser desejada, para que novas interpretações sobre o assunto cheguem até a escola.

Percebe-se uma tentativa de mudança nessa abordagem, como no caso do livro Novo olhar - História, que menciona as reflexões de Kant sobre o Iluminismo e as críticas contemporâneas ao Iluminismo. No entanto, o cerne de sua explicação fica pautado por tentar produzir um modelo e um sistema explicativo acerca daquele passado. Nos outros livros, a tentativa de ampliação do campo de possibilidade para análise do iluminismo parece não ser nem ao menos considerada.

Redefinir a própria ideia de Iluminismo foi, talvez, a maior inovação da revisão historiográfica sobre o tema. Se, mesmo na época, era notável a incapacidade de definir o conceito, deve-se repensar o por quê de se querer tanto enquadrá-lo em um único esquema de explicação. O Iluminismo não pode ser encarado como um fenômeno unitário, como disse Himmelfarb, nem no campo acadêmico, muito menos no da educação básica.

\section{Referências bibliográficas}

BOULOS JÚNIOR, Alfredo. História, sociedade e cidadania. 1ª Ed. São Paulo: FTD, 2011.

CARVALHO, Flávio Rey de. Revisitando o iluminismo: contribuições para o estudo do caso português. Disponível em: http://revistatempodeconquista.com.br/documents/RTC5/FLAVIOREY.pdf. Acesso em 21 de fevereiro de 2013.

FARIA, Ricardo Moura; MIRANDA, Mônica Liz; CAMPOS, Helena Guimarães. Estudos de História: Ensino Médio. $1^{\text {a }}$ Ed. São Paulo: FTD, 2010.

HIMMELFARB, Gertrude. Os caminhos para a modernidade. São Paulo: Realizações Editora, 2011.

ISRAEL, Jonathan. O iluminismo radical. São Paulo: Mandras, 2009.

KNAUSS, Paulo. Por onde anda a História na atualidade da escola: ensino médio, livros didáticos e ensino de história. In. ROCHA, Helenice; MAGALHÃES, Marcelo e GONTIJO, Rebeca. A escrita da História escolar. Rio de Janeiro: FGV, 2009, p. 293-308.

MIRANDA, Sonia Regina e LUCA, Tânia Regina. O livro didático de história hoje: um panorama a partir do PNLD. In Revista Brasileira de História. São Paulo, v. 24, nº 48, p.123-144, 2004.

MUNAKATA, Kazumi. Deve os livros didáticos de história ser condenados? In: ROCHA, Helenice; MAGALHÃES, Marcelo e GONTIJO, Rebeca. A escrita da História escolar: memória e historiografia. Rio de Janeiro: FGV, 2009, p.281-292.

PELLEGRINI, Marco César; DIAS, Adriana Machado; GRINBERG, Keila. Novo olhar - História 2. $1^{\text {a }}$ Ed. São Paulo: FTD,2011.

OUTRAN, Dorinda. O Iluminismo. Lisboa: Temas e debates, 2001.

POCOCK, J.G.A. Barbarian and religion. Cambridge: Cambridge University Press, 2003. Vol.1.

SORKIN, David. The religious Enlightenment: protestants, jews and catholics from London to Viena. Oxford: Oxford University Press, 2008.

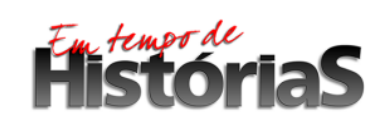


VILLALTA, Luiz Carlos. O livro didático de história no Brasil: perspectivas de abordagem. In Pós-História: Revista de Pós-Graduação em História (Unesp), (9): 39-59, Assis, 2001.

WITHERS, Charles W.J. Placing the englightenment: thinking geographically about the age os reason. Chicago e Londres: The Chicago University Press, 2007. 